before and after the application of all electric procedures $(\mathrm{p}<$ 0.001). By the application of galvanic current knee pain was evaluated as 80.25 before the therapy and it was reduced to 33 after PT. Modulated currents application led to pain reduction from 82 to 33 , and interferrent currents application from 88.5 to 37.5 .

However there was no significant difference in analgesic effect between the different procedures.

As far as the joint swelling is concerned, it has been reduced for $1-3 \mathrm{~cm}$ in $57 \%$ of the patients after the application of galvanic current, in $89 \%$ after modulated current and in $83 \%$ after interferrent current.

Physicians evaluated the effect of the electric therapy with the mean grade of 4.2 by patients and with 4.05 .

Conclusion Electric therapy has a statistically significant influence in the pain reduction in rheumatoid patients, but there is not a significant difference between them. It is an inexpensive therapy without side effects and it has to be in use more then it was until now.

\section{HP0021 ACUPUNCTURE IN A RHEUMATOLOGY CLINIC}

${ }^{1}$ RE Alexander, ${ }^{2}$ AR White. ${ }^{1}$ Rheumatology, Edgware General Hospital, Middlesex, UK; ${ }^{2}$ Complementary Medicine, University of Exeter, Exeter, UK

\subsection{6/annrheumdis-2001.1296}

Background The first author was asked to set up an Acupuncture Clinic for a limited period, within a Rheumatology Department of Barnet and Chase Farm Hospital Trust. She had been practising acupuncture for fifteen years and had recently joined the department. An audit was taken as there are few published trials on Rheumatology Clinic patients. ${ }^{1}$

\section{Objectives}

- To assess response of pain to acupuncture, alongside recording patients' analgesic intake.

- To assess whether the duration of pain or x-ray changes denoted a better result.

Method A course of four to six sessions of traditional and myofascial acupuncture was offered, for a specified range of conditions, using electro-acupuncture after the first treatment. Average pain during the day and night was recorded weekly on a scale of 1 to 10 , as well as the number and type of analgesics taken. An audit was analysed of the outcome for a series of 41 patients, who had a mean age of 57 years and pain for a mean duration of three years.

Results The mean score for daytime pain fell from 6.8 (SD 1.2) to 4.9 (SD 2.5) points, which is highly significant ( $<<0.001)$. A total of $30(73 \%)$ of the patients had a reduction in pain of at least $33 \%$ and $22(54 \%)$ had a reduction in pain of at least 50\%. Analgesic intake, (without distinguishing between different analgesic medication), was reduced from a mean of 17 (SD 15.3) tablets per week, to a mean of 6 (SD 7.9). Patients with normal $\mathrm{X}$-rays had a much better response to acupuncture than those whose $\mathrm{x}$-rays showed significant degenerative changes.

Conclusions Over $65 \%$ of patients referred for acupuncture to a designated clinic showed a significant improvement after treatment and were able to reduce their intake of analgesic drugs. Patients with moderate or severe degenerative changes on $\mathrm{x}$-ray did not respond as well as those with $\mathrm{x}$-rays showing no abnormality.

\section{REFERENCE}

1 Berman BM, Swyers JP, Ezzo J. The evidence for acupuncture as a treatment for rheumatologic conditions. Rheum Dis Clin North Am. 2000;26:103-15 